\title{
Two cases of primary bilateral malignant melanoma of the choroid
}

\author{
STEFAN SEREGARD,' CARL DAUNIUS, , ERIK KOCK,' AND \\ VLADISLAV POPOVIC
}

From the 'Department of Ophthalmology, Karolinska Hospital, Stockholm; the ${ }^{2}$ Department of Ophthalmology, Vänersborg-Trollhättan Central Hospital; and the ${ }^{3}$ Department of Ophthalmology, Sahlgrenska Hospital, Gothenburg, Sweden

SUMmARY The first two Swedish cases of primary bilateral malignant melanoma of the choroid are presented. In one case bilateral histological confirmation was obtained as both eyes were enucleated. In the other case one eye was enucleated and the other irradiated with an episcleral ruthenium plaque. Sweden has a population of 8.38 millions, so that bilateral choroidal melanomas may be less rare than previously thought.

The annual incidence of unilateral malignant melanoma of the choroid is $5-7.5$ per million Caucasians. It is much less frequent in a nonCaucasian population. Bilateral choroidal malignant melanoma is consequently believed to be extremely uncommon. It has been estimated to occur once every 18 years in the United States. ${ }^{1}$ A few cases world-wide have been described, ${ }^{2-6}$ some of them associated with other primary malignancies. ${ }^{78}$ In some other cases metastases from a cutaneous melanoma simulated bilateral primary lesions. ${ }^{9}$

We present two cases of primary bilateral malignant melanoma of the choroid, presumably the first two Swedish cases reported.

\section{Case reports}

CASE 1

A 72-year-old woman had had blurring of vision in the right eye for the past week. The physician admitting her to hospital noted a choroidal mass in the lower half of her right eye extending from the equator to the macula. There was a similar but smaller lesion in the lower temporal quadrant of her left eye located somewhat more anteriorly.

The visual acuity was hand movements in the right eye and 20/20 in the left eye. Diascleral transillumination proved negative in the right eye but positive in the left eye. Echography and fluorescein angiography

Correspondence to Dr S Seregard, Department of Ophthalmology, Karolinska sjukhuset, Box 60500, 10401 Stockholm, Sweden. demonstrated findings suggestive of malignant melanoma in both eyes.

She was otherwise in good health, and orbital CT scan, liver scan, abdominal ultrasound, bone scan, and chest $x$-ray failed to reveal anything abnormal.

Owing to extensive tumour growth the right eye was enucleated in March 1980. Pathological examination of the eye showed a pigmented tumour $9 \times 9 \times 11 \mathrm{~mm}$ in size mainly composed of epithelioid cells. Tumour growth was noted in the deeper parts of the sclera and Bruch's membrane was ruptured. There was no extrascleral extension. The left eye was irradiated in July with an episcleral plaque of ruthenium-106, and the tumour promptly regressed.

After a cataract extraction in March 1985 the patient has retained a visual acuity of $20 / 30$. She is still in good health with no signs of systemic illness.

CASE 2

An 86-year-old man was first examined by an ophthalmologist in May 1975 when he complained of blurred vision in both eyes. Visual acuities were noted to be $20 / 40$ in the right eye and 20/200 in the left eye. The visual disturbance was due to yellow spots, presumed to be degenerative changes, in both macular regions. In November the patient reappeared with deteriorated visual acuity, namely hand movements in the right and 20/200 in the left eye. The yellowish lesions now appeared solid and slightly protruding; the right eye had an associated retinal detachment.

The patient's history included previous surgery for a carcinoma of the rectum. No treatment was 
given, as the protruding growths were regarded as metastases.

Four months later the patient presented with severe pain in his right eye. A high intraocular pressure not responding to therapy was noticed, and, as only perception of light remained, the eye was enucleated.

Nothing was heard of him until 1980, when he reappeared with pain in the remaining left eye due to raised intraocular pressure. The visual acuity was reduced to perception of light, and the eye had to be enucleated.

Both enucleated eyes were histopathologically examined. The right eye contained a choroidal malignant melanoma $9 \times 9 \times 9 \mathrm{~mm}$ in size. The tumour was composed of spindle B cells and penetrated Bruch's membrane, but there was no extrascleral extension. His left eye showed a similar spindle cell melanoma $12 \times 10 \times 10 \mathrm{~mm}$ in size. Here also Bruch's membrane was ruptured. The tumour infiltrated the sclera but did not grow extrasclerally.

There was no search for extraocular metastases, but the patient is still in remarkably good health, without clinical signs suggesting metastatic disease. He is now 97 years old.

\section{Discussion}

The first case report illustrates the current trend in Sweden to treat choroidal melanomas in a conservative manner. Episcleral plaques containing ruthenium-106 have been used in Sweden since 1979 to treat medium sized choroidal melanomas. In such cases there is no histological confirmation of the diagnosis unless treatment fails and the eye is enucleated. However, in the first case the clinical appearance was undoubtedly that of a choroidal melanoma, and this was substantiated by ultrasonography and fluorescein angiography. Furthermore, the tumour responded promptly to irradiation therapy.

In the second case both eyes were enucleated, and consequently we obtained bilateral histological confirmation. It is interesting to note that metastatic spread has not occurred, despite enucleation in a late stage.

As noted above, bilateral malignant melanoma of the choroid is rare. The population of Sweden is $8 \cdot 38$ millions, so that bilateral tumours may occur somewhat more often than previously thought.

\section{References}

1 Schammas HF, Watzke RC. Bilateral choroidal melanomas. Arch Ophthalmol 1977; 95: 617-23.

2 Shine FW. Report of a case of bilateral sarcoma of the uveal tract. Clin Rep NY Eye Ear Infirm 1930; 1: 31-3.

3 Lau T. Das primär doppelseitige maligne Melanom der Choroidea. Klin Monatsbl Augenheilkd 1981; 179: 333-5.

4 Oosterhuis JA. Primary choroidal and cutaneous melanomas, bilateral choroidal melanomas, and familial occurrence of melanomas. Br J Ophthalmol 1982; 66: 230-3.

5 Ide CH, Ford T, Oxenhandler RW, Havey A, Adelstein EH. Gleichzeitiges bilaterales malignes Melanom der Choroidea ohne ursprünglichen Nachwis von Metastasen. Fortschr Ophthalmol 1983; 80: 304-8.

6 Migdal C, MacFarlane A. Bilateral primary choroidal melanoma. Br J Ophthalmol 1984; 68: 268-71.

7 Tsukahara S, Wakui K, Ohzeki S. Simultaneous bilateral primary diffuse malignant uveal melanoma: case report with pathological examination. BrJ Ophthalmol 1986; 70: 33-8.

8 Mullaney J, Mooney D, O'Connor M, McDonald GSA. Bilateral ovarian carcinoma with bilateral uveal melanoma. $\mathrm{Br} J$ Ophthalmol 1984; 68: 261-7.

9 de Bustros S, Augsburger JJ, Shields JA, Shakin EP, Pryor CC. Intraocular metastases from cutaneous malignant melanoma. Arch Ophthalmol 1985; 103: 937-40.

Accepted for publication 26 June 1987. 